NEWS AND NOTES

\section{Health Canada Secretariat for Injury Prevention and Control}

Canada now has a national focal point for injury prevention, with the announcement in late January of a Health Canada Secretariat for Injury Prevention and Control. Working under the health ministry, the secretariat is charged with developing a national framework for injury prevention in Canada. Exactly what that means awaits the outcome of consultations across this vast land. It could at the least include securing improved collaboration among the various branches of Health Canada through which injury work is now fragmented, and among other government departments which play a part in injury prevention, such as transport, agriculture, and justice. Although a budget for national programming is lacking, the secretariat is staffed by three well known practitioners whose experience brings together three elements of injury prevention (surveillance and research, public education, and community action): Francine Archambault, who previously managed national public education programs for the health protection branch of Health Canada; Margaret Herbert, an epidemiologist who managed CHIRPP, Canada's emergency department injury surveillance system; and Morag Mackay, an injury epidemiologist who also built a community injury prevention program in the Ottawa area. Their goal is to have a national plan ready for the Montreal world conference in 2002.

\section{QISU reviews shopping trolley injuries}

Fall from shopping trolleys are a significan preventable cause of head injury in young children, notes the Queensland Injury Surveillance Unit, reporting a pattern of injury similar to that seen in the US. The most common injury scenario involves a fall from the basket or child seat of the trolley. In a small number of cases the trolley was reported to have toppled over either on to the child or while the child was riding in it. To address the problem, new Australian/New Zealand standard AS/NZS 3847.1:1999 has been published. However, its adoption is voluntary and some researchers comment that it only addresses some of the injury scenarios, omitting the problem of lateral loading from children climbing or swinging on the sides of the trolley.

\section{Snowmobile training to be monitored}

Young people who ride snowmobiles or all-terrain vehicles (ATVs) are the target of an injury prevention program in western Manitoba, reports the winter edition of Manitoba Child Injury Prevention News (a publication packed full of so many interesting items that these columns cannot do justice to it). Impact, the injury prevention centre of Children's Hospital, Winnipeg, has joined with the Marquette Regional Health Authority to implement and evaluate a program of safety training for riders over the next 12 months. Research has shown that drowning is a major cause of snowmobile related death, especially during freeze-up and spring thaw. Injuries to young snowmobile and ATV drivers usually involves excessive speed, alcohol, night driving, driver inexperience, or riding on the highway. There is room for improvement in helmet wearing rates. Details of the program can be obtained from im-pact@escape.ca.

\section{Product related injuries in the elderly}

Monash University has produced another valuable document, Consumer Product-Related Injuries in Older Persons (Watson, Day, Ozanne-Smith, Lough). The parallels with children are striking. Most occur in their homes; the products involved in falls are concrete and other outdoor surfaces, flooring, and stairs. Beds and chairs are also associated with falls, as are rugs, runners, mats, and footwear. Not surprisingly, most falls from heights are from ladders, and in light of the editorial, it is noteworthy that alcohol was associated with $7.5 \%$ of fall fatalities. Of nonfall fatalities, heaters, cigarettes, baths, showers, sofas, and lounges are implicated, whereas for non-fatal, non-fall injuries, the most frequent product are power saws, lawn mowers, dogs, and knives.

\section{New helmet design}

A radical new idea could improve the effectiveness of motorcycle crash helmets. The design incorporates an elastic skin on the exterior of the helmet that is capable of moving independently from the hard layers underneath. This gives added protection in impacts where the brain is forced to rotate in the skull - that is, when the rider's head hits the road or a glancing blow from a vehicle. Sound familiar? It is modelled after the human scalp.

\section{New Zealand Injury Prevention Network} Coordinator appointed

Being a little late with some of my reading, I have just noticed that the Christmas issue of Safekids News carries a feature on the appointment of Pania Shingleton as the coordinator for the NZ Injury Prevention Network. Pania, whose background is a mix of journalism, public relations, marketing and health promotion, is based in Whangarei. The deadline for setting up the network as a legal entity is July 2000 . If you want to join the New Zealand injury prevention network e-mail list, send an e-mail to listproc@stonebow.otago.ac.nz, don't put a subject or a signature. In the message type subscribe nzinjuryprevention YourFirstName YourLastName.

\section{Second death from Pokemon balls prompts second recall}

The US Consumer Product Safety Commission (CPSC) and Burger King Corporation have again urged consumers to immediately destroy and discard Pokemon balls distributed with Burger King kids meals in the USA in November and December 1999. In January 2000, a 4 month old boy in Indianapolis, Indiana, reportedly suffocated when one half of a Pokemon ball that was in his crib became stuck on his face. Burger King issued a voluntary recall of more than 25 million Pokemon balls on 27 December 1999. The balls pose a suffocation hazard to children under 3 years of age. In December, a 13 month old girl reportedly suffocated when one half of a Pokemon ball covered her nose and mouth. Also in December, an 18 month old girl nearly suffocated when a ball half got stuck over her face. On the second attempt, the girl's father was able to pull the ball half from her face. Pokemon balls are plastic, ball shaped containers between 2.75 and 3 inches in diameter. They pull apart to reveal one of 57 different Pokemon toys inside.

\section{Canadian injury research agenda}

A further gear has been added to power Canada's injury prevention efforts. A cross country group of researchers (including the editor of this journal) has been funded by the Medical Research Council to develop a national agenda for injury research in Canada. The hope for this major initiative is that it will fuel productive injury research by encouraging cross pollination in this multidisciplinary field, by attracting more young scientists to work in injury prevention, and by linking with the public policy and community program sectors to get research turned into action. Currently injury in Canada receives $1 \%$ of national research funds, despite accounting for $11 \%$ of the economic burden of illness. The working group plans to learn from the Americans and Australians, who have been through similar national strategic efforts.

\section{Kidsafe Week secure for three years}

New Zealand's highly successful Kidsafe Week has achieved a secure funding for at least three years. The Health Funding Authority, Accident Compensation Commission and the Land Transport Safety Authority have all agreed to provide long term funding contracts, allowing Safekids, as the coordinating agency, to plan ahead more effectively.

\section{"Weeks" diary dates}

Child Safety Week (UK): 19-25 June 2000 Contact Child Accident Prevention Trust (csw@capt.demon.co.uk for details).

Kidsafe Week (New Zealand): 13-20 October 2000. (Details via the Safekids web site, www.safekids.org.nz, as the otherwise excellent Safekids News seems to have omitted all e-mail and postal addresses!)

\section{Air guns are dangerous}

Although not news for many, a recent study reminds us that air gun injuries are frequent and may be serious. Of 162 injuries caused by guns over a seven year period in Columbus, Ohio, 87 were caused by airguns; 42 were hospitalized and of these half required surgery. Thirteen suffered permanent visual damage.

\section{Good news and less good news from} WHO

The good news is that the World Health Organisation (WHO) has just released a col- 
ourful and informative monograph, Injury: $A$ Leading Cause of the Global Burden of Disease. This excellent document, edited by Etienne Krug, originates in the Violence and Injury Prevention Division of the Department for Disability/Injury Prevention and Rehabilitation programme. To construct the tables that form the core of the document, a tree structure was formulated using data from the WHO World Health Report 1999 database. Both mortality and disability adjusted life years (DALYs) are presented. The latter combine the number of years of life lost from premature death with the loss of health from disability. The graphics showing the results clearly demonstrate the importance of injuries among the 15 causes of death and burden of disease. The only minor criticism I have is the age grouping used: although putting 5 to 14 year olds together is tolerable, taking the next group as 15 to 44 years is much less so because it makes it impossible to examine adolescents separately.

The less good news is found in a press release from WHO entitled Sex, Drugs and Potato Crisps. The title says it all. The findings are those of the latest WHO Youth Health Survey based on data from 28 countries. Although the core questionnaire addressed a wide variety of health issues, including tobacco and alcohol use, medication, exercise, eating, etc, information about injuries was left to the discretion of each country. Hence we know more about sex, drugs, and potato chips as health problems among adolescents than we do about injuries. Presumably, this does not reflect WHO's priorities; what seems most likely is that there is less than ideal communication between the Health Promotion and Investment for Health Division and the group involved with injuries.

\section{Impulsive children have more injuries}

A news release from the Center For The Advancement of Health describes a study in which 59 children were evaluated at ages 33 months, 46 months, and again at age 6 years. A standard battery of tests assessed inhibitory control and extraversion. At 6 those who scored high on the latter and low on the former overestimated their physical abilities and experienced more injuries requiring medical attention. The conclusion is that injury prevention programs should target these children, but fails to suggest what should be done. The study reinforces the findings from several older reports pointing to much the same traits as risk factors.

\section{Cooler Canada}

Turning down domestic hot water heaters to $49^{\circ} \mathrm{C}$ has long been advocated as a primary means of preventing tap water scalds, particularly among vulnerable elderly and infant populations. Public education campaigns on this strategy, however, have had limited success. Ensuring that hot water tanks are pre-set to safer temperatures before they leave the factory holds more promise by eliminating the problem at its source. Currently in Canada, hot water heaters are typically pre-set at temperatures guaranteed to scald the very young and the very old within seconds of delivery at the tap. But a change to the National Plumbing Code, which would require safer pre-set temperatures, has so far eluded Canadian activists.
Now two initiatives are underway aimed at changing national policy. As part of a campaign called "Hot Water Burns Like Fire", Safe Start (the injury prevention program of British Columbia's Children's Hospital) has secured the support of the provincial government in lobbying for changes to the national plumbing code. At the same time, a coalition of national organizations is working towards the same goal. Led by SafeKids Canada, this effort also includes the Canadian Institute for Child Health, Smartrisk, and Safe Start. For more on the "Hot Water Burns Like Fire" campaign, contact Safe Start at www.childhosp.bc.ca/ Children's/safestart.

\section{Impact of Safekids Week demonstrated}

An evaluation by the University of Otago's Injury Prevention Research Centre showed that New Zealand's Kidsafe Week hit the mark - target audiences were reached, awareness raised, and behaviour changes that impact positively on child safety resulted. Some key findings were that there was a $76 \%$ general awareness of the week, there was a very high recall of resources sent to school principals, and over half of councillors and community board members are likely to make changes in policies and practices as a result of the week. Contact Safekids via their web site, www. safekids.org.nz, for more details.

\section{Preventing falls in seniors}

In addition to the wise advice arising from the paper on falls in the March issue, the National Center for Injury Prevention and Control in the US has recently issued a "tool kit" to prevent senior falls. It includes several fact sheets ("Falls in nursing homes", "Falls and hip fractures", "The costs of fall injuries"), two leaflets ("What you can do to prevent falls", and "A home fall prevention checklist for older adults"). The suggestions range from placing phones where they can be reached after a fall to the removal of throw rugs, objects on the floor, wearing sturdy shoes, improving lighting, placement of cords and wires, non-slip mats for tubs and showers, and much more. All of these make good sense but interestingly, few, if any, have been subjected to study whereas the use of hip protectors are not mentioned. A minor criticism of what seems, in general, an excellent resource.

\section{More on fractures}

In another report, we learn that smoking retards the healing of fractures. In Canada, the most common fracture treated by orthopaedic surgeons are those involving the wrist.

\section{Consumers perception of the CE mark}

The January/February issue of the ANEC newsletter reports on a European Commission survey of 15000 citizens who were asked about their perceptions of the CE mark. While awareness of the mark was high on electrical products and toys, there was widespread misunderstanding of its meaning - only $15 \%$ knew that the safety checks on products carrying the mark were carried out by manufacturers themselves, with half thinking that the controls were car- ried out by the commission! A depressing finding for the commission must have been the fact that two thirds of respondents said they never take the mark into account when buying a product and only $10 \%$ take guidance from it often or always.

Editor's note: The mark is actually largely irrelevant for consumers as the sale of consumer products covered by marking requirements without the mark is illegal in the EU!

\section{Another Australasian Safe Community}

The city of Melbourne, Australia, is poised to become the 50th member of the WHO Safe Community Network. Melbourne proudly takes its position as the first state capital in the southern hemisphere to join the movement-after Anchorage, Alaska, in the north. Melbourne has a long history of working with the resident community on challenging social issues-drugs, alcohol, taxis, nightclubs, and public safety issues. The accreditation ceremony of Melbourne will involve Victoria's Head of Government, Premier Steve Bracks, and a number of government ministers as well as the Lord Mayor and City Chief Executive Officer. Professor Leif Svanström, Director of the WHO Collaborating Centre on Community Safety Promotion in Sweden will officiate. The ceremony will also see Melbourne host the third international symposium on applying the Safe Community concept in large urban environments. Monash University Accident Research Centre and Melbourne's Royal Children's Hospital Safety Centre (as WHO Safe Community Affiliate Support Centres will host an international meeting of Safe Community Evaluation and research personnel.) The Victorian Safe Communities Network (which hosts the annual Community Safety Week in Victoria, 3-9 September 2000) will also participate by hosting a travelling seminar which will take in Melbourne City Safety, Hume City, Wangaratta City, the City of Greater Dandenong and finally a visit to the Shire of La Trobe. Both La Trobe and the City of Hume are accredited WHO Safe Community Network Members. For more information check the internet web site for the Collaborating Centre at www.ki.se/phs/ wcc-csp Victorian Safe Communities Network at www.general.monash.edu.au/muarc/ $\mathrm{vscn} / \mathrm{vscn} / \mathrm{html}$

\section{Alcohol policy web site}

Alcohol use and injuries have often been linked, but beyond drink driving campaigns and legislation, little of this concern has found its way into public policy. That is the part of the premise behind the Alcohol Policy Network, a public health coalition in Ontario, Canada. One member is the Association to Reduce Alcohol Promotion in Ontario (ARAPO), which urges the public to voice concerns about alcohol advertising, especially where children can receive the messages. The Alcohol Policy Network has a useful and chock-full web site at www.apolnet.web.net.

\section{How to transport children in hip spicas}

Children in hip plasters are usually difficult and sometimes impossible to squeeze into an infant car seat. Various attempts to adapt 
seats have been made, but none seem entirely satisfactory. A possible solution is the E-Z-ON (TM) Adjustable Vest-a product that is also being advocated for use on school buses. Having examined the material it seems evident that the vest is preferable to no restraint; whether it is the best possible solution for children in spicas, or those on buses, remains to be established through proper study.

\section{Falling children}

A not too surprising study reveals that children who fall from significant heights suffer fracture patterns that vary with age and differ from those seen in adults. The peak age for fall injuries among children is 2 years. In general, infants and toddlers tend to land head first whereas those older than 11 sustain more injuries to the legs, pelvis, and spine. The group in between - ages 3 to 10 - sustain long bone injuries.

\section{A new injury hazard}

Trust the Australians to come up with this one! Apparently the latest unrecognised hazard of life in warm countries is ceiling fans One hospital in north Queensland treated 50 patients in the last two years with fan inflicted injuries, many of which arose from failing to turn the fan off before painting the ceiling or while fixing the fan. Too much sun?

\section{EU boost for car safety}

EU Transport Commissioner Loyola de Palacio has told members of the European Parliament that she intends to come forward with concrete proposals on pedestrian protection legislation soon. ANEC and other transport safety campaigners have welcomed the announcement.

\section{CPSC promotes SIDS deaths initiative}

To prevent deaths from soft bedding, seven major retailers have joined the US CPSC in kicking off a safety campaign promoting safe bedding practices for babies. As many as 900 baby deaths each year attributed to sudden infant death syndrome (SIDS) may actually be caused by suffocation in soft bedding, such as quilts, comforters, pillows, and sheepskins. The retailers, which account for the majority of baby bedding sales, have made changes to crib displays in retail stores, catalogues, advertisements, and web sites. From spring 2000, shoppers have not been able to see cribs made up with pillows, quilts, and comforters. Many retailers now include cautionary statements about the use of soft bedding for younger babies in their catalogues, on signs attached to cribs, and on inserts that accompany baby comforters and quilts.
When babies are featured in crib ads, they will always be pictured sleeping on their backs. Other retailers are going to create bedding safety brochures for customers and add quilt racks to their nursery product lines. Since 1994, the CPSC has warned about the danger of soft bedding to babies under 12 months. But when consumers went to stores or browsed through catalogues, they often got a different message. Cribs made up with comforters, quilts, and pillows may have encouraged parents to use these items in the crib with an infant. Parents unaware of the warnings would not know that these items could be deadly for young babies. For babies under 12 months, CPSC, the American Academy of Pediatrics and the National Institute of Child Health and Human Development recommend the following to help reduce the risk of SIDS:

- Place baby on his/her back on a firm, tight fitting mattress in a crib that meets current safety standards.

- Remove pillows, quilts, comforters, sheepskins, pillow-like stuffed toys, and other pillow-like soft products from the crib.

- Consider using a sleeper as an alternative to blankets with no other covering.

- If using a blanket, put baby with his or her feet at the foot of the crib. Tuck a thin blanket around the crib mattress, only as far as the baby's chest

- Make sure your baby's head remains uncovered during sleep.

- Do not place baby on a waterbed, sofa, soft mattress, pillow, or other soft surface to sleep.

The CPSC has worked with manufacturers to get warning labels on infant pillows, and is now working for a similar warning on baby quilts and comforters.

\section{Fatally struck by a puck}

A 5 year old child died after he was hit in the chest by a hockey puck. Apparently it resulted in cardiac arrest. The child was wearing full protective hockey gear but the shot, by an adult, was forceful enough to be fatal.

\section{Australian youth in focus}

Here's a snapshot of the health, safety, and wellbeing of Australian youth in 1999:

- Injury rates for the age group15-24 years are high compared with other age groups.

- Young people aged 15-24 years have the highest prevalence of injuries of all age groups.

- The difference in injury rates between males and females varies by age; the ratio of male to female injury death and hospitalisation rates for the age group 15-24 years is 3.5 and for $24-35$ years 3.7 .

- The injury death rate for young males aged 12-24 years has decreased substantially from just over $100 / 100000$ in 1979 to $62 / 100000$ in 1992 and remains at around that level.
- The injury death rate for young females has fallen from $28 / 100000$ in 1979 to $18 /$ 100000 in 1997.

- The gender differential in injury death rates for young people has not changed greatly over the period 1979-97 ranging between 3.2 and 4.2 .

- For the age group 12-24 years, death rates are highest at 18-24 years for both males and females.

- Hospitalisation rates are highest for 17-24 year olds of both sexes.

- In 1997 motor vehicle crashes were the most common cause of injury related death for females and second most common for young males; for males suicide was the most common cause.

- Injuries to young people caused by violence are a relatively common reason for hospitalisation; the overall mortality rate associated with violence was around $2 / 100000$, higher for males than females.

- A higher proportion of young people were victims of assault than for the whole population in 1996, with a rate for young males of just under 1500/100 000 compared with $700 / 100000$ for all males and 1100/ 100000 for young females compared with under 500/100 000 for all females.

- Injury shows a marked gradient across socioeconomic disadvantage groups (except quintile 3) with young people in quintile 5 having 1.8 times the death rate of those in quintile 1 ; transport related deaths (2.2) and suicide (1.5) were the largest components.

- The overall death rate for young people aged 15-24 years who were born in Australia was 1.2 times higher than for those born overseas; the injury rate ratio was 1.2 , but for violence it was lower at 0.7 . In summary, Australia's young people are in good health and it is improving, but there are still some areas of concern, some groups are comparatively worse off, and gender differences continue.

(Source: Moon L, Meyer P, Grau J. Australia's young people: their health and wellbeing 1999. Canberra: Australian Institute of Health and Welfare, 1999).

Child passenger safety bill introduced in US Congress

More realistic to testing of child restraints, protection for 8-12 year olds and a rating system for restraints are among the features being called for in a Bill presented to the US Senate in February.

Contributors to these News and Notes include: Barry Pless, Ian Scott, Jan Shield, Kathy Weber, and Amy Zierler. Michael Hayes has edited the contributions. Zierler. Michael Hayes has edited the contributions. Items for the December 2000 issue should be sent to Michael Hayes at the Child Accident Prevention Trust, $18-20$ Farringdon Lane, London EC1R 3HA, UK (fax: +44 (0) 207608 3674, e-mail: mh@capt.demon.co.uk) by 1 September 2000. 